\title{
A parametrização como experiência prévia para a estruturação de métodos projetuais em arquitetura
}

Parametrization as previous experience for structuring design methods in Architecture

\author{
> Tássia Borges de Vasconselos \\ UFPel, Brasil \\ tassiav.arq@gmail.com \\ > Adriane Almeida da Silva Borda \\ UFPel, Brasil \\ adribord@hotmail.com
}

\author{
$>\quad$ Luisa Félix Dalla Vecchia \\ UFPel, Brasil \\ luisafelixd@gmail.com
}

\begin{abstract}
This study describes a didactic method for the introduction of parametric design in graphic and digital geometry courses in architectural training. It started with the recognition of the concept of parametric design and the investment in the appropriation of Grasshopper associated with Rhinoceros. Paper folding exercises were configured both physically and in the digital space. Through an interactive dynamic between traditional processes, by hand and digital, and parametric design, a learning path was defined in a playful manner which highlights the differences between methods of representation and its implications for the design action starting from a first semester of training.
\end{abstract}

Keywords: Parametric Design; Teaching/learning; Graphic and Digital Geometry; Architecture; Paper Folding.

\section{Introdução}

A inserção de práticas de desenho paramétrico junto ao contexto da Faculdade de Arquitetura e Urbanismo da Universidade Federal de Pelotas é recente. Estas práticas foram introduzidas em atividades de pós-graduação e extensão, incluindo algumas incursôes em disciplinas de graduação, através de atividades pontuais, descritas em Brod, Pires e Borda (2012). Tais incursôes foram ensaios oriundos de trabalhos de investigação na área de representação, através de experimentaçóes junto às disciplinas de Geometria Gráfica e Digital III e de Informática Aplicada II e não propriamente na área de Projeto.

Desta maneira, considera-se que a infraestrutura construída até então, junto ao contexto em questão, é insuficiente para promover que o desenho paramétrico se estabeleça como um método. Por um lado, está a pouca experiência didática, dos docentes envolvidos, neste tema específico. Por outro, e quase como consequência, a falta de material didático contextualizado para a ação docente.

O desenho paramétrico impóe uma mudança de paradigma, inicialmente para a área de representação. Pensar a forma a partir de algoritmos que acionam transformaçóes espaciais sobre entes geométricos, mesmo que traduzidos por uma linguagem visual de programação, efetivamente não é o mesmo que pensar a forma através da linguagem gráfica e de procedimentos projetivos.

Considera-se necessário gerar uma cultura não exatamente transitória, no sentido de determinar uma futura substituição dos métodos tradicionais. Mas, uma cultura paralela, por se entender evidente a potencialização mútua dos exercícios cognitivos estabelecidos no âmbito de cada método. Sob esta perspectiva, este trabalho delimita um problema didático de identificar e/ou estruturar atividades que promovam o desenvolvimento da cultura referida.

Partindo-se do reconhecimento de estudos como o de Casale e Valente (2012), . busca-se introduzir o conceito de desenho paramétrico através de práticas com origami. Desta maneira, promovendo-se experiências com a manipulação de modelos digitais de dobraduras em papel.

A ideia é de que estas experiências promovam a construção de um repertório significante, como os blocos Froebel representaram para a formação de Frank Lloid Wright. Este arquiteto atribuiu importância para sua formação ao fato de ter brincado em sua infância com tais blocos: "Um pequeno mundo interior de cor e forma veio apoderar-se dos pequenos dedos. Cor e padrôes, no plano e no contorno. Formas escondidas atrás da aparência de todas elas." (WRIGHT, 1998 - p.32)

Brincar com o origami, mesmo no espaço físico, parece evidenciar uma lógica do desenho paramétrico. Justifica-se, desta maneira a intenção de trabalhar com estes conceitos em estágios iniciais de formação, promovendo efetivas experiências cognitivas. Avançar para a manipulação de dobraduras no espaço digital, explicita efetivamente o conceito de desenho paramétrico.

\section{Materiais e Métodos}

O estudo está sendo guiado então pelo objetivo de construir uma cultura de reconhecimento das potencialidades do desenho paramétrico como método de representação, em seu sentido mais amplo de ação projetual, já em estágios iniciais de formaçáo em arquitetura. 
Optou-se em dirigir o estudo para uma disciplina de primeiro semestre de formação: Geometria Gráfica e Digital II (GGD II), buscando-se assim avançar na experiência relatada em Brod, Pires e Borda (2012), a qual foi realizada em uma disciplina de segundo semestre. A GGD II se propóe a abarcar os conceitos e procedimentos tradicionais e digitais relativos ao sistema de projeção paralelo ortogonal, incluindo assim o método de projeção cotada e o biprojetivo, envolvendo exclusivamente o estudo de formas poliédricas. Desta maneira, os estudantes envolvidos estão ainda reconhecendo os diferentes sistemas de representação. Deve-se destacar a conveniência de se ter o corpo docente da disciplina como coautor deste trabalho.

O estudo ficou caracterizado a partir das seguintes etapas: revisão bibliográfica; desenho das atividades didáticas; experimentação; análise e sistematização dos resultados.

\section{Revisão bibliográfica:}

Especialmente os estudos registrados em Santos et al (2012), Pereira e Vaz (2013) e Casale, Valenti e Calvano (2014) subsidiaram o processo de reconhecimento dos conceitos e procedimentos de desenho paramétrico necessários a serem introduzidos em contextos de ensino de arquitetura.

Conforme referido anteriormente, a partir de Casale e Valente (2012), os exercícios com dobraduras de papel a partir do desenho paramétrico foram identificados como apropriados para serem associados aos exercícios didáticos desenvolvidos no âmbito da disciplina GGD II.

\section{Desenho das atividades didáticas:}

Tradicionalmente, no âmbito da disciplina GGD II utiliza-se o tema de coberturas para introduzir o método de projeção cotada. O estudo dos sistemas era proposto de maneira sequencial: cotada e, logo, o bi-projetivo. Entretanto, ao trazer o conceito de parametrizaçáo para a reestruturação das atividades didáticas questionou-se esta linearidade, buscando desenhar outra trajetória. A proposta foi de abordar tais conteúdos em paralelo, buscando evidenciar as potencialidades e limitaçóes de cada um. A atividade didática introdutória à disciplina partiu então da representação em dobraduras de papel, por permitir, tanto seguir fazendo uma alusão às coberturas como facilitar a inserção de conceitos de parametrização.

Os exercícios de representação passaram a incluir então a execução do modelo físico (dobradura propriamente dita em papel), as projeçóes (cotada e biprojetivo) utilizando-se de diferentes meios: pelo processo tradicional a mão; pela representação digital através do uso do software Sketchup; através de desenho paramétrico utilizando o Grasshopper associado ao Rhinoceros.

Levou-se em conta que as habilidades necessárias para o uso das ferramentas de desenho paramétrico poderiam desestimular estudantes de estágios iniciais de formação. Desta maneira, partiuse da hipótese de poder disponibilizar tais ferramentas como um ambiente semelhante ao de um jogo, um ambiente de descobertas em que a configuração em Grasshopper já é fornecida aos estudantes, cabendo a eles manipular os parâmetros para encontrar as formas inicialmente determinadas pela dobradura física.
Foram propostos, entáo, dois jogos a serem desenvolvidos. Um deles baseado na proporçấo raiz de dois em que os origamis são construídos a partir de uma folha A4. Neste caso foi estabelecido como regra de trabalhar exclusivamente com dobras paralelas ao sentido menor da folha. O outro jogo parte de um quadrado. Para este formato de folha as dobraduras só podem estar definidas sobre as direçóes das diagonais do quadrado e sobre as bissetrizes destas diagonais. Passou-se a tratar cada um como: jogo de dobraduras paralelas e jogo de dobraduras radiais. Especialmente, a partir de Casale e Valente (2014) e da consulta aos fóruns de discussóes sobre desenho paramétrico, foi possível constituir os dois jogos. A configuração de tais jogos está sendo disponibilizada junto aos mesmos fóruns pesquisados, buscando-se compartilhar e discutir sua funcionalidade e otimização.

\section{Э. Э. Experimentação:}

A experimentação foi desenvolvida no primeiro semestre de 2014. Inicialmente com a dobradura da folha raiz de dois e logo com a dobradura da folha quadrada. Como etapa prévia das duas atividades os estudantes tiveram que explicitar os parâmetros que definiram a localizaçáo de cada uma das dobras, em vale ou montanha, de acordo com a terminologia dos origamis. Promoveu-se a adoção de lógicas para as dobras relativas ao próprio formato do papel, abordando-se essencialmente os conceitos de proporção e recursão para incrementar o repertório de ação projetual dos estudantes. Cada estudante registrou, através de fotografia digital, pelo menos duas soluçóes de dobraduras para os dois formatos de papel, seguindo as regras previamente impostas. A figura 1 exemplifica este tipo de registro.

Para cada um dos dois tipos de dobraduras (paralelas e radiais) as atividades propostas foram desenvolvidas em três fases: a) Utilização de técnicas tradicionais à mão, pelo método de cotada e bi-projetivo, cujos parâmetros geométricos ficam implícitos ao desenho. As representaçóes são estáticas, no sentido que a cada posição relativa entre os elementos do sistema de projeção ou de variação das dobras existe a necessidade de um redesenho. O tipo de representação produzido nesta fase de desenvolvimento está exemplificado também junto à figura 1 ; b) Utilização de técnicas digitais a partir do software SketchUp. Consideradas, no âmbito deste trabalho de semi-dinâmicas, especialmente por exigir a transposição dos procedimentos manuais ao ambiente digital. Comenta-se junto aos estudantes sobre a lógica desta ferramenta de facilitar a configuração das formas a partir de transformaçóes por extrusão. E, que para o caso em questão, de necessidade de manter a figura (retângulo raiz de dois ou o quadrado) em sua proporção original, mesmo depois das dobraduras, tal facilidade não pode ser aproveitada. Desta maneira, o discurso didático procura destacar a necessidade de adotar um método de representação que controle a operação de dobra, sem variar as dimensóes da folha. Por outro lado, com as vantagens de representaçôes digitais tridimensionais, após a configuração da forma no espaço digital, obtém-se automaticamente as representaçóes sobre diferentes pontos de vista. Investe-se em operaçóes de controle dos parâmetros de projeçáo até a compreensão de obtenção de imagens em perspectiva, como ilustrado na figura 2. O método de representação das dobraduras 

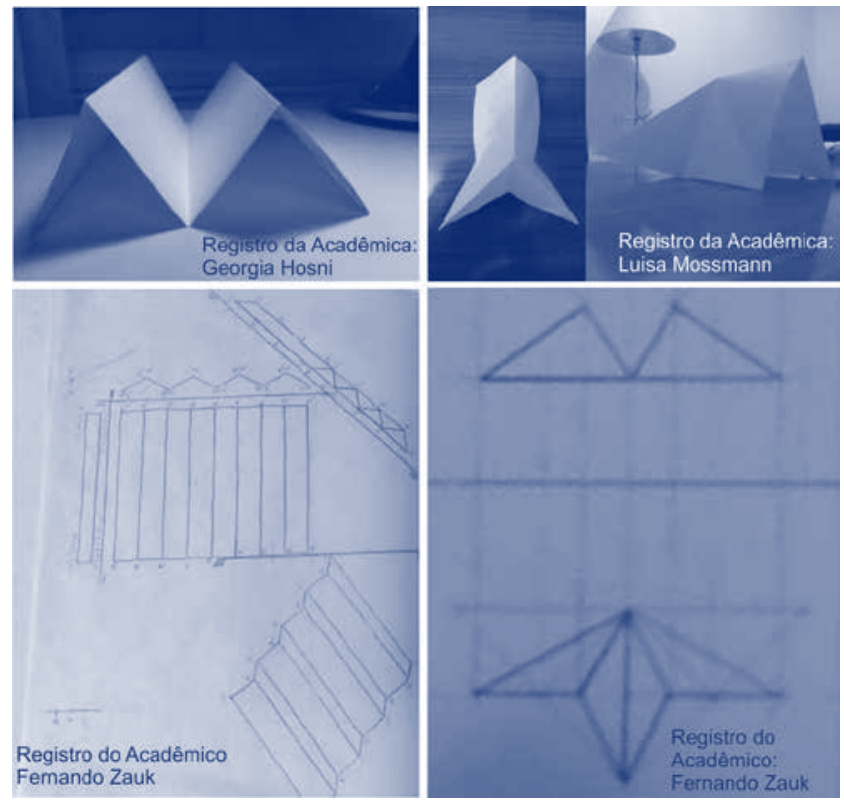

Figura 1: Registro da atividade de construção do modelo físico.

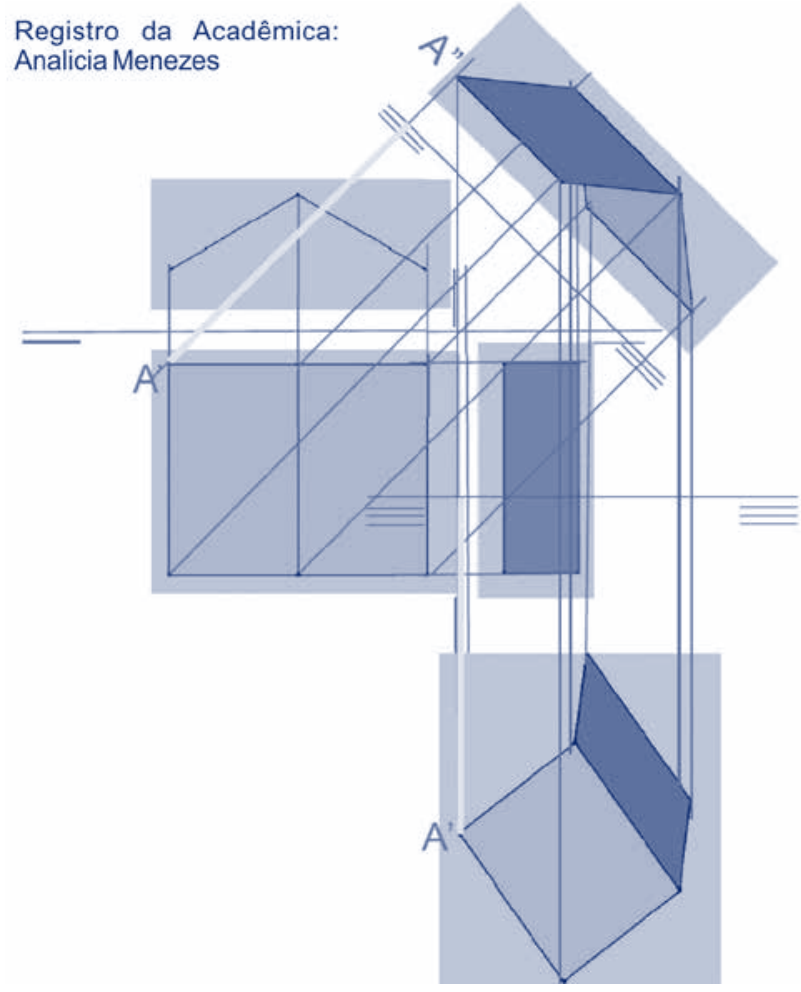

Figura 2: Registro da sequencia de açôes realizadas para a representaçấo de dobraduras no SketchUp.

a partir desta ferramenta digital foi sendo induzido a partir da fase anterior, demonstrando-se a possibilidade de rotacionar a partir da vista frontal, tal como se pode deduzir da ilustração, em épura, da figura 1; c) Utilização das técnicas de desenho paramétrico, tendo-se os parâmetros explícitos e representaçôes dinâmicas, através então dos dois jogos anteriormente referidos. Os estudantes experimentam

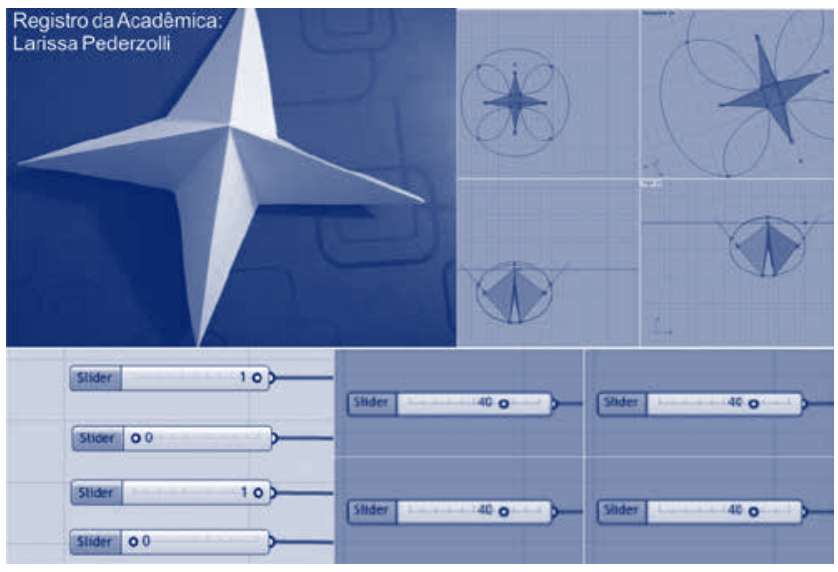

Figura 3: Registro do origami físico e virtual "o jogo", origami radial.

estas técnicas a partir do software Rhinoceros associado ao Grasshopper. A figura 3 exemplifica a representação de uma dobradura radial, a partir de seu modelo físico e de seu modelo virtual concebido através do "jogo", incluindo-se a explicitação dos parâmetros utilizados pelo estudante. As figuras 4 e 5 ilustram representaçôes controladas pelos estudantes, os quais buscaram reproduzir, em um primeiro momento, cada um de seus projetos inicialmente idealizados e registrados nas fotografias. Logo, seguiram investigando diferentes possibilidades, observando a lógica da ação de cada um dos parâmetros envolvidos sobre a forma.

\section{Resultados e Discussões}

Os resultados até entáo obtidos podem ser observados em termos qualitativos de aprendizagem. Em semestres anteriores, em que os estudantes aprendiam primeiro o método de projeção cotada para depois iniciarem o aprendizado do método bi-projetivo, percebiase o uso isolado de cada método. No âmbito da experiência aqui referida, os quais foram abordados paralelamente, percebeu-se a associação entre os métodos, recorrendo a procedimentos complementares de acordo com a conveniência do momento de resoluçáo do problema de representação.

Em semestres anteriores já se vinha utilizando a representação digital através do uso do software Sketchup, o que vinha apresentando um resultado positivo. Entretanto, com a introdução do desenho paramétrico e a visualização em tempo real de qualquer alteração nos parâmetros, foi possível avançar ainda mais na compreensão espacial por parte dos estudantes. Vários estudantes relataram ter compreendido melhor os desenhos que estavam fazendo em épura (a mâo) depois de ter manipulado "o jogo" podendo visualizar as mudanças que aconteciam nas vistas com a manipulação dos parâmetros.

É importante destacar que este experimento está sendo aplicado, agora pela segunda vez, neste segundo semestre de 2014, buscando-se aperfeiçoá-lo e gerar resultados que permitam realizar análises quantitativas também.

Os jogos, especialmente, estão sendo revistos, pois apresentaram alguns problemas de configuração. No de dobraduras paralelas, por exemplo, era possível aumentar ou diminuir as laterais do retângulo 

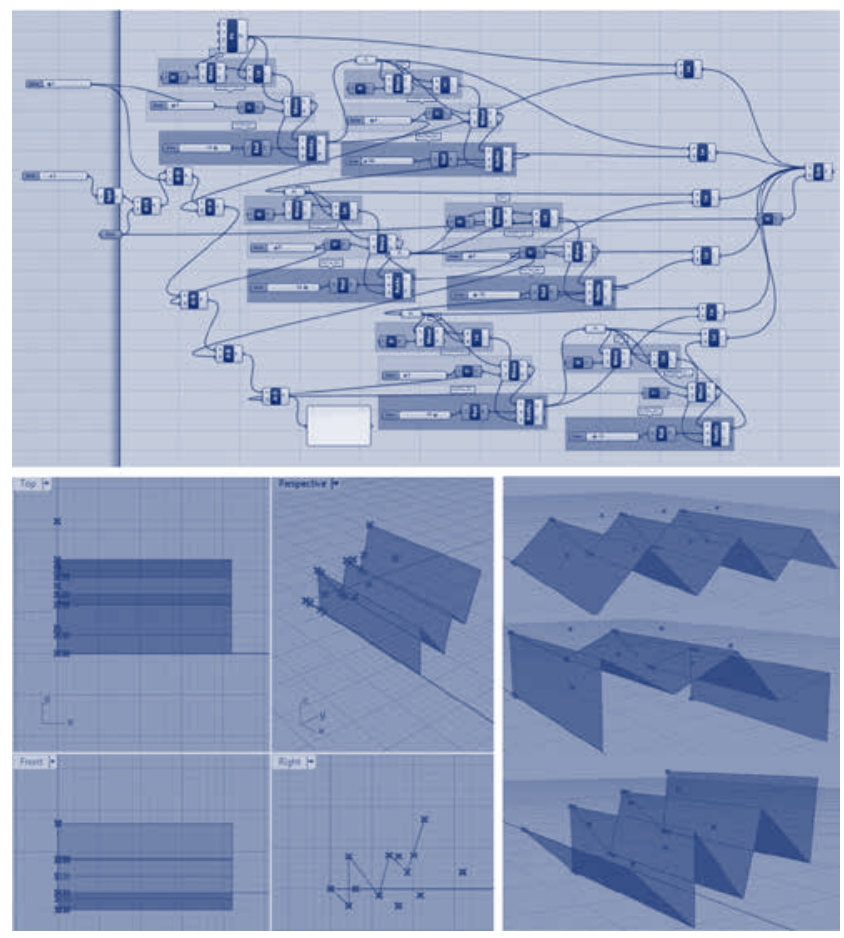

Figura 4: Registro da atividade "o jogo" origami paralelo.

raiz de dois. Esta falha foi percebida durante a aplicação da atividade e teve-se que orientar os estudantes para que não manipulassem tal parâmetro. Para o jogo com dobraduras radiais, as regras apresentadas aos estudantes estáo sendo revistas, para excluir casos em que o sistema configurado não prevê. Por exemplo, alguns estudantes dobraram o papel em uma das diagonais do quadrado sobrepondo totalmente os dois lados, o que fez com que efetivamente partissem de um triângulo, possibilidade esta que não havia sido prevista na configuração em Grasshopper.

Apesar dessas dificuldades encontradas, a motivação dos estudantes para o aprendizado de todo o conjunto de representaçóes foi notadamente maior que em semestres anteriores. A ação cognitiva exigida para o aprendizado de um tipo de representação foi se mostrando complementar e potencializadora para o aprendizado dos demais, permitindo avançar na compreensão real sobre a forma tratada. O receio inicial de introduzir raciocínios geométricos complexos já em um primeiro momento de formação foi substituído pelo propósito de aperfeiçoar cada vez mais a experiência. Foi interessante perceber a compreensão dos estudantes para o enfrentamento dos problemas operacionais, entendendo-se que isto se deve à motivaçáo de reconhecer as possibilidades do desenho paramétrico, como um método, complexo, porém ágil para a ação projetual.

\section{Considerações Finais}

Os estudos com desenho paramétrico, no contexto de desenvolvimento deste trabalho, são recentes e tem desencadeado o estabelecimento de um ambiente de reestruturação conceitual e procedimental no âmbito de disciplinas de representação gráfica e digital. De tal maneira que grande parte das atividades didáticas
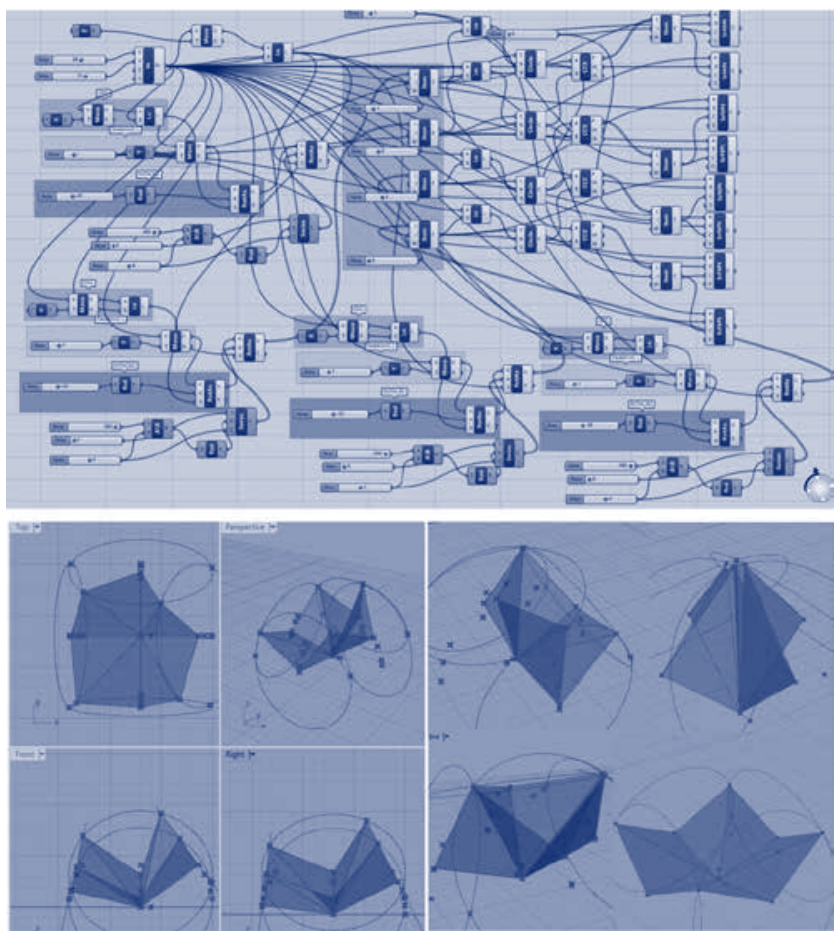

Figura 5: Registro da atividade “o jogo” origami radial.

estáo sendo permeadas pelas reflexôes advindas de tais estudos. Estas reflexóes apontam especialmente para a valorizaçáo de saberes que paulatinamente foram sendo retirados das grades curriculares de arquitetura. Referem-se aos exercícios de lógicas formais, de operações matemáticas associadas às transformações espaciais, para as quais, anteriormente, não se tinham instrumentos facilitadores para possibilitar compreender sua aplicabilidade e importância. As atividades desenvolvidas tem explicitado tais saberes e demonstrado maneiras de reincorporá-los com significado para a formaçáo em arquitetura.

O fato do campo de investigaçáo se restringir ao âmbito de disciplinas de representação e não propriamente de projeto, tem permitido investir na construçâo de um repertório prévio à ação projetual.

Desta maneira o estudo pode contribuir para motivar outros contextos similares que ainda não tenham buscado a inserção do conceito de desenho paramétrico em estágios iniciais de formação pela compreensão de que a parametrização pode ser interpretada como ação investigativa para o projeto. Podendo auxiliar para que paulatinamente, junto ao processo formativo, se constitua como um método de projeto. Método capaz de adicionar inúmeros parâmetros para então abarcar, em estágios mais avançados de formação, a complexidade da arquitetura.

A hipótese é de que a experiência proporcionada aos estudantes, de compreensão do desenho paramétrico, em um primeiro momento de formação em arquitetura, ative a lógica de pensar a forma de maneira associativa e conceitual. E, até este momento, considera-se que a experiência realizada comprovou a hipótese de sua capacidade em promover a compreensão dos limites e potencialidades de cada 
um dos métodos de representaçáo envolvidos, assim como suas complementaridades para a ação projetual.

Os estudos até então desenvolvidos permitem compreender as potencialidades do conceito de desenho paramétrico para a ação projetual e especialmente destacar a conveniência de reconhecimento deste conceito em estágios iniciais de formação em arquitetura, tendo-se em vista a proposta intrínseca de se estabelecer como mais um método de projeto.

Isto para que o aprendiz, através da experiência concreta com a forma a partir da multiplicidade de abordagens tecnológicas para o controle da geometria, adquira competências prévias ao processo de pensar/representar o espaço arquitetônico e urbano.

\section{Agradecimentos}

Agradecemos ao Programa de Pós-graduação em Arquitetura e Urbanismo da Universidade Federal de Pelotas e ao Ministério da Educação (CAPES) pelo apoio a esta pesquisa. Especialmente, agradecemos aos processos formativos em desenho paramétrico oportunizados às autoras, pelos professores arquitetos Ernesto Bueno, Gabriela Celani e Carlos Vaz.

\section{Referências}

Casale A.. Valenti, G.M., Calvano M. Castelli di carta. (2012) La piega per la costruzione di superfici articolate House of cards.
The fold for the construction of articulated surfaces in: DISEGNARECON: Geometria - Costruzione - Architettura, vol 5 no9 pag: 289 à 300. Acesso em: http://disegnarecon.unibo.it/ BROD, G., PIRES, J. , BORDA,A. (2012) Um ensaio para inserção do conceito de processos generativos digitais em estágios iniciais da formação em arquitetura In: XVI SIGRADI - Congresso da Sociedade Ibero Americana de Gráfica Digital. Forma(in)formação. Fortaleza: Expressão Gráfica e Editora, v.01. p.611 - 614

Casale A.; Valenti, G.M.; Calvano M. Architettura Delle Superfici Piegate - le geometrie che muovono gli origami. Edizzione Kappa, 2014.

Pereira, D. C., VAZ, C. E. V., Parametrismo e ensino de geometria- as superfícies de Felix Candela. In: Simpósio Nacional de Geometria Descritiva e Desenho Técnico e International Conference on Graphics for Arts and Design, 2013, Florianópolis. Tecnologia e Arte para Inovaçã. Florianópolis. 01-09. Acessado em: http://wright.ava.ufsc.br/-grupohipermidia/ graphica2013/anais.html

Santos, A. C., VAZ, C. E. V., Pereira, D. C., Duarte, M. E. R., Pinheiro, J. V.L. (2012). O uso das ferramentas de desenho paramétrico no ensino de geometria gráfica - $\mathrm{O}$ caso dos poliedros. Gráfica del diseño - Tradición e inovaciónes, 291- 294.

WRIGHT, Frank Llody.(1998) Autobiografia, 1867[1944]. Edición em castellano. Madrid: El Croquis Editorial. 